\title{
A Metalloprotease from Xanthomonas campestris That Specifically Degrades Proline/Hydroxyproline- Rich Glycoproteins of the Plant Extracellular Matrix
}

\author{
J. Maxwell Dow, Huw A. Davies, and Michael J. Daniels \\ The Sainsbury Laboratory, John Innes Centre, Colney Lane, Norwich, NR4 7UH, U.K. \\ Accepted 15 July 1998.
}

\begin{abstract}
Culture supernatants of Xanthomonas campestris pv. campestris contain an enzymic activity capable of degrading gp120, a proline-rich glycoprotein associated with the extracellular matrix of the vascular bundles in petioles of turnip (Brassica campestris). This activity did not reside in any of the three previously characterized proteases of $X$. campestris pv. campestris that were identified by their action against the model substrate $\beta$-casein. The novel enzyme was purified by ion-exchange and size-exclusion high-performance liquid chromatography (HPLC). The enzyme, which has no activity against $\beta$-casein, is active against some plant glycoproteins of the hydroxyprolinerich class such as extensin from potato and tomato and gpS-3, a glycoprotein induced in $B$. campestris petioles by wounding. Other hydroxyproline-rich glycoproteins, such as the solanaceous lectins, were not substrates however. Studies of the products released upon degradation of tomato extensin suggested that the degradative mechanism was proteolysis. Inhibitor studies suggested that the enzyme was a zinc-requiring metalloprotease. Extracellular matrix glycoproteins of the proline-rich and hydroxyproline-rich classes have been implicated in plant resistance to microbial attack, hence their degradation by $X$. campestris pv. campestris may have considerable significance for black rot pathogenesis.
\end{abstract}

Additional keywords: immunoanalysis, monoclonal antibodies, Western analysis.

The plant extracellular matrix has a central role in the inter-
action of plants with both pathogenic and symbiotic microor-
ganisms. This matrix contains several classes of glycoprotein
in addition to the more abundant polysaccharide components.
Two classes of matrix glycoprotein, the hydroxyproline-rich
glycoproteins (HRGPs) and proline-rich proteins (PRPs), have
been particularly implicated in plant resistance mechanisms to
pathogen attack (reviewed by Bowles 1990; Showalter 1993).
Immobilization of pathogens through binding to extracellular
HRGPs (Leach et al. 1982; Mellon and Helgeson 1982;
Swords and Staehelin 1993) or PRPs (Millar et al. 1992) and
strengthening of the extracellular matrix by enhanced deposi-
tion and cross-linking of HRGPs (Esquerré-Tugayé et al.

Corresponding author: J. M. Dow; E-mail: dowm@bbsrc.ac.uk
1979; Showalter et al. 1985) or by cross-linking of preexisting PRPs (Bradley et al. 1992; Brisson et al. 1994) have been suggested to contribute to plant defense. Changes in expression of these extracellular matrix glycoproteins also accompany differentiation of plant tissue and may have roles in determining wall rigidity and consequently resistance of particular tissues to pathogen invasion. Many microbial plant pathogens synthesize and export arrays of enzymes that can degrade polymers of the plant extracellular matrix (reviewed by Walton 1994). These enzymes may have roles in pathogen ingress, disease progression, or symptom development. Although HRGPs and PRPs are considered to contribute to plant defense, there is little direct work on the counteractive ability of pathogens to degrade these glycoproteins or on the role of degradation in plant pathogenesis. In many cases, the ability of pathogens to degrade defense-related (glyco)proteins is inferred from their ability to degrade model substrates such as gelatin or casein.

We are interested in the interaction between turnip (Brassica campestris) and the bacterium Xanthomonas campestris pv. campestris, the causal agent of black rot disease of crucifers (Williams 1980). We have recently described several extracellular matrix glycoproteins of $B$. campestris petioles of the PRP and HRGP classes. gp120 is a proline-rich glycoprotein that contains low levels of hydroxyproline and is predominantly associated with vascular bundles of petioles (Davies et al. 1997a). gpS-3 is an HRGP that is induced in the petiole by wounding and in response to avirulent pathogens (Davies et al. 1997b). gp120 contains arabinose and galactose as predominant sugars with lower levels of xylose. gpS-3 contains predominantly arabinose with much lower levels of galactose and trace amounts of xylose. Both of these glycoproteins can be detected immunologically with a panel of monoclonal antibody probes. Studies of the interaction of gp120 with $X$. campestris pv. campestris have led to the detection of an enzyme activity in bacterial culture supernatants that could rapidly degrade the glycoprotein. This activity does not reside in any of the three previously characterized extracellular proteases of $X$. campestris pv. campestris, which were all identified with $\beta$-casein as a model substrate. We report here the characterization of this novel $X$. campestris pv. campestris enzyme as a metalloprotease that is active against the HRGP gpS-3 as well as HRGPs from a number of different plant sources. 


\section{RESULTS}

Detection of an enzyme activity in $X$. campestris culture supernatants that can degrade the glycoprotein gp120.

Extracts made from petioles of $B$. campestris by homogenization in $100 \mathrm{mM}$ Tris-HCl buffer $\mathrm{pH} 8.5$ contain two glycoproteins (gp120 and gp45) that have different mobilities on sodium dodecyl sulfate-polyacrylamide gel electrophoresis (SDS-PAGE) but that are both immunoreactive with the monoclonal antibody MAC204 (Davies et al. 1997a). In addition, gp120 but not gp45 is recognized by the monoclonal antibody MAC236. In initial experiments, the ability of ammonium sulfate-concentrated culture supernatants of wild-type $X$. campestris pv. campestris strain 8004 and the prtA mutant strain 8524 to degrade these glycoproteins was assessed by SDS-PAGE and immunoanalysis with MAC204 and MAC236.

The glycoprotein gp120 as detected by MAC204 and MAC236 was almost completely degraded within 10 min after mixing with the supernatant preparation from both strains, although gp45 was not degraded. The results with the supernatants from the prtA mutant are shown in Figure 1. No degradation of gp120 or gp45 was evident on incubation of the petiole extract alone in the absence of $X$. campestris culture supernatants. These results suggest that the degradation of gp120 was not due to the action of plant enzymes present in the petiole extract nor to PRT1, the serine protease encoded by prtA.

\section{The previously characterized proteases PRT1 and PRT3} of $X$. campestris cannot degrade gp120.

Three proteolytic enzymes have been detected in $X$. campestris pv. campestris strain 8004 by their action on $\beta$-casein: the serine protease PRT1 and two zinc-requiring metalloenzymes PRT2 and PRT3 (Dow et al. 1990, 1993). PRT3 is a minor protease in this strain. The action of each of these different proteases on $\beta$-casein gives rise to a characteristic pattern of peptides as revealed by SDS-PAGE, which is suggestive of different peptide bond specificities. Incubation of gp120 with isolated recombinant PRT1 caused no detectable degradation (data not shown). This is consistent with the absence of an effect of mutation of prtA on gp120 degradation by $X$. campestris pv. campestris culture supernatants. In addition, purified PRT3 was unable to degrade gp120. Although purified PRT2 is not available, fractionation of the culture supernatant from $X$. campestris pv. campestris by cationexchange chromatography did resolve the gp120-degrading activity from PRT2 activity (see below). gp120 was not degraded by trypsin nor by the protease from the fungal Brassica spp. pathogen Pyrenopeziza brassicae (Ball et al. 1991; A. Hunter and K. Johnstone, unpublished).

\section{Partial purification of the enzyme activity.}

The culture supernatant of strain 8524 was used as the source of the gp120-degrading enzyme activity as the low proteolytic activity of this strain allows increased recovery of other proteins from the culture supernatant. After concentration by ammonium sulfate precipitation and dialysis, the sample was applied to a column of DEAE-Sephadex to remove colored and viscous material, as outlined in Materials and Methods. The eluate containing the unbound proteins and the gp120-degrading activity, was fractionated by cation-exchange high-performance liquid chromatography (HPLC) on SP-5PW at $\mathrm{pH}$ 5. Fractions were analyzed for proteolytic activity against $\beta$-casein, gp120-degradative activity, and endoglucanase activity. Endoglucanase is the major extracellular protein produced by $X$. campestris pv. campestris strains 8004 and 8524 in NYGB medium (Gough et al. 1988) and is a convenient marker for correct protein binding and elution. As expected, endoglucanase activity coincided with the major peak of absorbance at $254 \mathrm{~nm}$, which eluted at approximately 0.12 $\mathrm{M} \mathrm{NaCl}$ (Fig. 2A). The maximum gp120-degrading activity was detected in fractions 18 and 19, eluting at approximately $0.15 \mathrm{M} \mathrm{NaCl}$ (Fig. 2B) and could be resolved from the proteolytic activity against $\beta$-casein that was absent in fraction 18 and maximal in fractions 20 and 21 (Fig. 2A,D). The pattern of peptides released from $\beta$-casein by the protease in these fractions demonstrated that this activity was due to PRT2 (Fig. 2D). Analysis of each of the fractions by SDS-PAGE and sil-

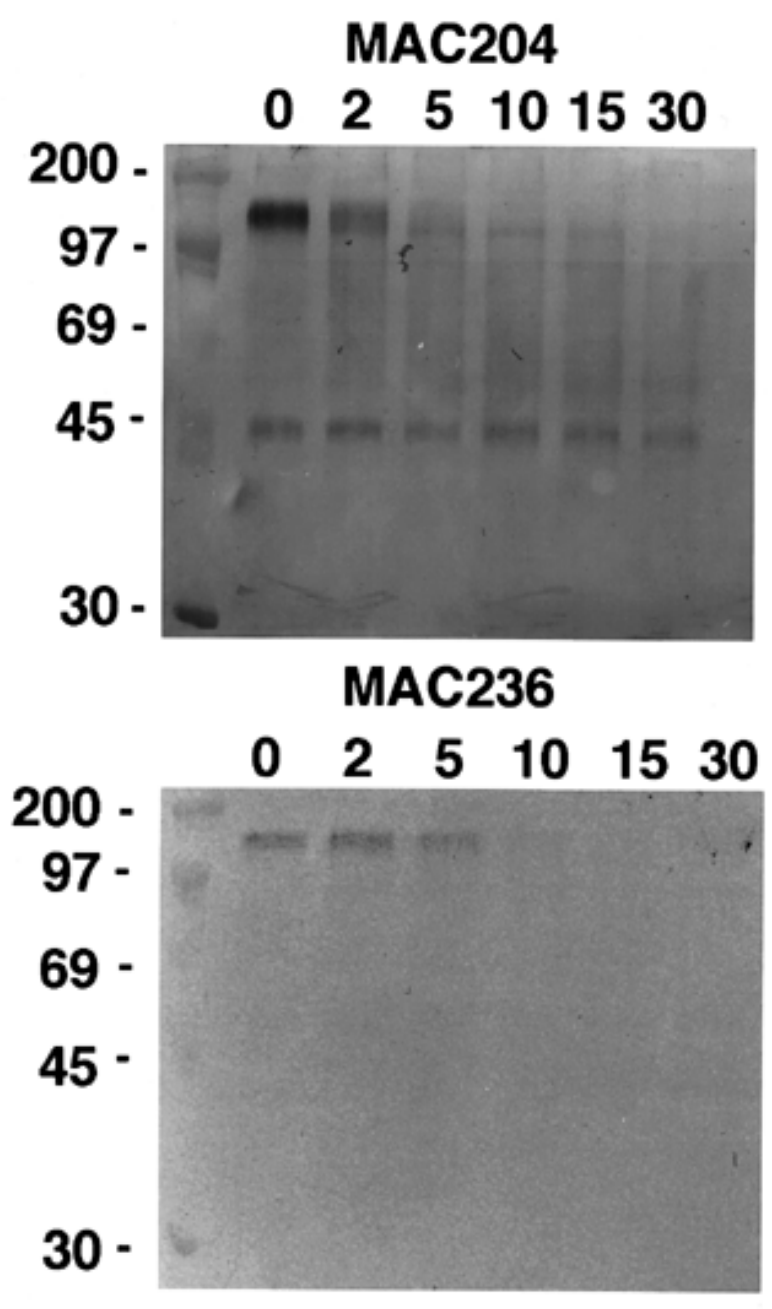

Fig. 1. Degradation of the glycoprotein gp120 by concentrated culture supernatants of Xanthomonas campestris pv. campestris strain 8524 (prtA) as monitored by Western (immunoblot) analysis with the monoclonal antibodies MAC204 and MAC236. Incubation times (in minutes) are given above each lane. The glycoprotein gp45 (which is detected by MAC204 alone) is not degraded. Molecular mass standards in $\mathrm{kDa}$ are given on the left-hand side. 
ver staining is shown in Figure 2C. Activity against gp120 was always associated with the presence of a major band with apparent molecular mass of $46 \mathrm{kDa}$, although there were other protein bands in the active fractions. (The protein of apparent molecular mass of $50 \mathrm{kDa}$ in fractions 18 and 19 is probably the tail of the very large peak of endoglucanase that has maximal concentration in fractions 13 and 14.)

Fractions 18 and 19 from the SP-5PW step were pooled, concentrated by use of a Centricon-30 microconcentrator, and subjected to size-exclusion HPLC on G3000SW $\mathrm{XL}_{\mathrm{XL}}$. Maximum gp120-degrading activity eluted from the column in fraction 21 , coincident with an absorbance peak at $254 \mathrm{~nm}$. Analysis of the fractions by SDS-PAGE and silver staining showed again that activity was associated with a major band (which appeared to constitute a doublet) with apparent molecular mass of $46 \mathrm{kDa}$ (Fig. 3). The N-terminal amino acid sequence of this protein band was determined to be IEQAFGDGVAV. Searches of the data bases with this sequence and both BLAST and FASTA algorithms revealed no significant homologies.
Other substrates for the gp120-degrading enzyme.

We were interested to determine whether the enzyme was active against other cell wall matrix glycoproteins of the proline/hydroxyproline-rich classes in addition to gp120. The effects of both ammonium sulfate-concentrated culture supernatants and the purified enzyme preparation on the degradation of these glycoproteins was assessed by Sephacryl column chromatography or SDS-PAGE followed by immunoanalysis to detect the glycoproteins, as outlined in Materials and Methods. The culture supernatant and purified enzyme had only weak activity against potato lectin and were unable to significantly degrade purified lectins from Datura stramonium and tomato (data not shown). The enzyme could degrade gp140, a PRP from wounded turnip disks (Fig. 4).

The degradation of purified tomato and potato extensin HRGPs and gpS-3, an HRGP purified from wounded B. campestris petioles, was assessed by column chromatography on Sephacryl HR400 followed by dot blot immunoanalysis of the fractions with the monoclonal antibodies JIM11 and MAC204. Treatment of all three glycoproteins with the crude
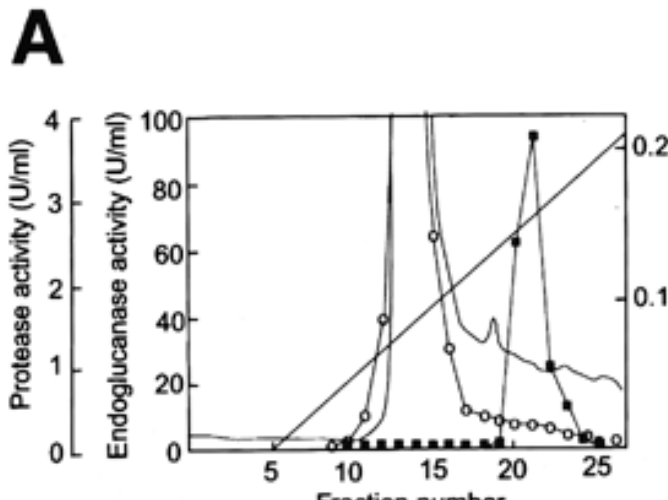

SDS-PAGE

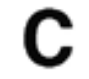
14

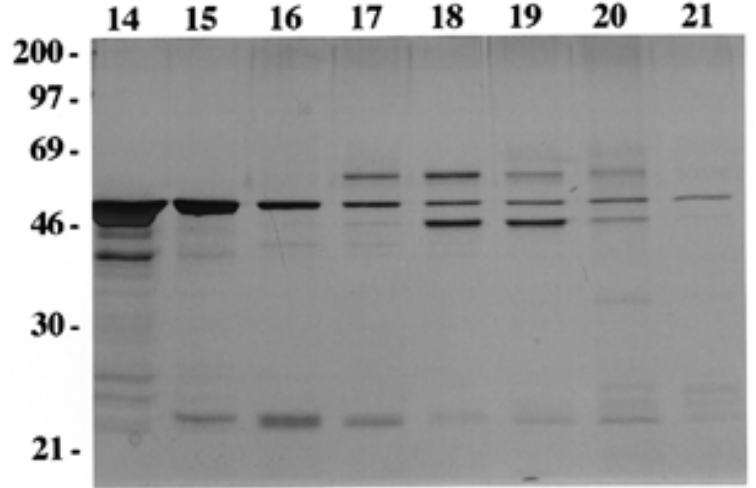

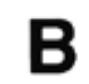
gP120 DEGRADATION
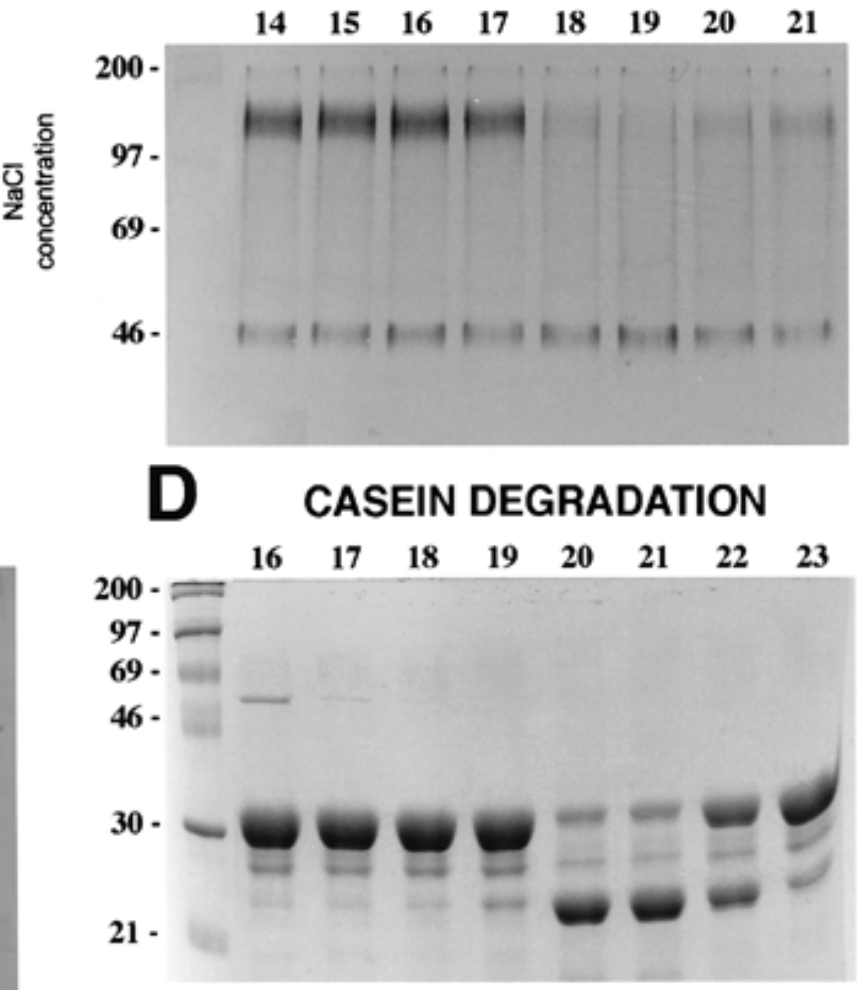

Fig. 2. Partial purification of the gp120-degrading activity from Xanthomonas campestris pv. campestris by ion-exchange high-performance liquid chromatography (HPLC) on SP-5PW at pH 5. Flow rate was $1 \mathrm{ml} / \mathrm{min} ; 1-\mathrm{ml}$ fractions were collected. A, Fractions were assayed for endoglucanase activity (open circles) and proteolytic activity against $\beta$-casein (filled squares). Solid line indicates $A_{254}$. Fractions with maximum gp120-degrading activity (as determined by Western [immunoblot] analysis) are indicated by shaded rectangle. B, gp120-degrading activity of fractions from the SP-5PW column as determined by Western analysis with the monoclonal antibody MAC204. Molecular mass standards in kDa are given on the left-hand side. Fraction numbers are given above lanes. Fractions 18 and 19 were pooled for size-exclusion chromatography. C, Sodium dodecyl sulfate-polyacrylamide gel electrophoresis (SDS-PAGE) of fractions from the SP-5PW ion-exchange chromatography. Gel was stained with silver. Fraction numbers are given above lanes; molecular mass standards in $\mathrm{kDa}$ are given on the left-hand side. $\mathbf{D}$, Patterns of degradation of $\beta$-casein by protease(s) in fractions revealed by SDS-PAGE and Coomassie blue staining. Assays were run for $30 \mathrm{~min}$. Fraction numbers are given above lanes; molecular mass standards in kDa are given on the left-hand side. 
culture supernatant or purified enzyme resulted in both a loss of immunoreactivity as estimated by dot blot analysis of unfractionated reaction mixtures and a shift in elution position of the remaining immunoreactive material to higher volumes. The results with gpS-3 and potato extensin as substrates are shown in Figure 5. These effects were not seen with boiled enzyme preparations. There was sufficient enzyme in $50 \mu \mathrm{l}$ of the ammonium sulfate-concentrated culture supernatant of $X$. campestris strain 8524 to degrade $100 \mu \mathrm{g}$ of potato extensin in $1 \mathrm{~h}$. Overall, these results suggest that the gp120-degrading enzyme is capable of degrading some, but not all, glycoproteins of the HRGP class.

\section{Characterization of the enzyme activity as a protease.}

Enzymatic degradation of proline- and hydroxyproline-rich glycoproteins could be achieved by either a glycanase or glycosidase activity that could remove the carbohydrate side chains or by a proteolytic activity capable of hydrolyzing the peptide backbone. It was not possible to distinguish between these possibilities from the properties of the enzyme so far described. The absence of activity of the purified enzyme against $\beta$-casein does not necessarily imply that the enzyme is not a protease. The monoclonal antibodies MAC204, JIM11, and JIM20 recognize periodate-sensitive epitopes on the glycoprotein substrates. Although these epitopes must at least in part constitute a carbohydrate moiety, we cannot infer that the loss of immunoreactivity seen on enzymatic degradation is solely due to the removal of carbohydrate residues. The purified enzyme preparation has no activity against the simple model substrates $p$-nitrophenol- $\beta$-D-galactoside and $p$ nitrophenol- $\alpha$-L-arabinofuranoside at a range of $\mathrm{pH}$ (data not shown).

To address the mechanism of action directly, we studied the effects of the enzyme on the purified tomato extensin of Brownleader and Dey (1993), a glycoprotein that has been more fully characterized than gp120. The carbohydrate moiety of this glycoprotein, which constitutes approximately $34 \%$ of the total weight, comprises largely arabinofuranosyl

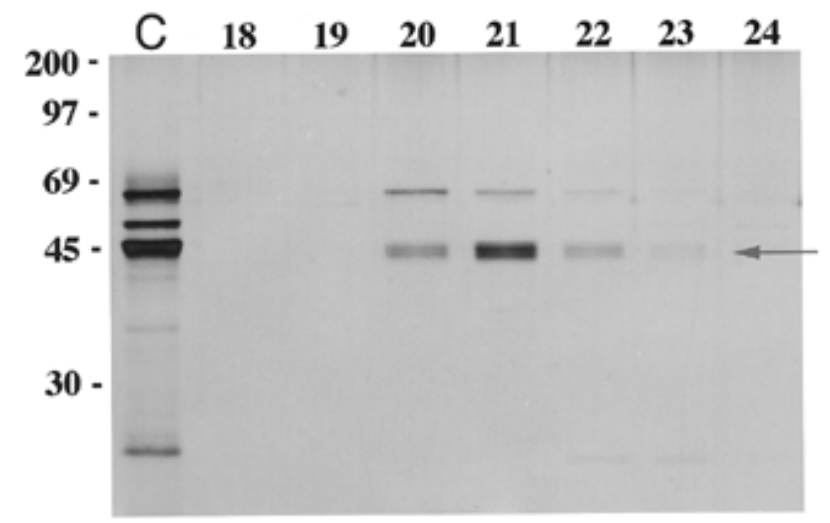

Fig. 3. Sodium dodecyl sulfate-polyacrylamide gel electrophoresis (SDS-PAGE) of fractions from G3000SW $\mathrm{XL}_{\mathrm{XL}}$ size-exclusion highperformance liquid chromatography (HPLC), the last step in the purification of the gp120-degrading activity from Xanthomonas campestris pv. campestris. Gel was stained with silver. Fraction numbers are given above lanes. An aliquot of the sample applied to the column was also run (lane C). Molecular mass standards in $\mathrm{kDa}$ are given on the left-hand side. Degradative activity against gp120 was always associated with the presence of a major band constituting a doublet of $46 \mathrm{kDa}$ (arrowed). residues $(95 \%)$ with about 5\% galactosyl residues (Brownleader and Dey 1993). The glycosylation most likely consists of single galactose residues attached to serine and mono- to tetra-arabinosides attached to hydroxyproline. We reasoned that the action of a glycosidase on tomato extensin would be expected to release neutral mono- or oligosaccharides whereas the action of a protease would be expected to release (glyco)peptides that would be charged. Two hundred micrograms of tomato extensin was digested with the purified enzyme for $3 \mathrm{~h}$ at $37^{\circ} \mathrm{C}$ in $50 \mathrm{mM}$ Tris- $\mathrm{HCl} \mathrm{pH} 8$. The reaction was terminated by heating at $100^{\circ} \mathrm{C}$ for $10 \mathrm{~min}$. As controls, extensin was incubated in buffer alone or with heat-inactivated enzyme. These reaction mixtures were passed through a mixed bed ion-exchange resin and subjected to high-performance anion exchange (HPAE) chromatography with pulsed amperometric detection (PAD). As a positive control, $200 \mu \mathrm{g}$ of tomato extensin was hydrolyzed with $0.1 \mathrm{M}$ trifluoracetic acid (TFA) at $100^{\circ} \mathrm{C}$ for $1 \mathrm{~h}$ to release monomeric arabinose (Brownleader and Dey 1993). After the TFA was removed by lyophilization, the residue was dissolved in $50 \mathrm{mM}$ Tris- $\mathrm{HCl} \mathrm{pH} 8$ and prepared for HPAE-PAD chromatography. Although a peak corresponding to monomeric arabinose could be detected in the TFA-hydrolyzed sample, no monomeric or oligomeric sugars were detected in the extensin sample after enzymatic degradation, in the extensin sample alone, or in the extensin sample treated with the heat-inactivated enzyme. This absence of neutral mono- or oligosaccharides as products of the degradation of tomato extensin suggests that the enzyme does not significantly degrade the carbohydrate portion of the glycoprotein.

Direct evidence that the enzyme degrades the peptide backbone of tomato extensin was obtained with an extensin preparation in which the proline and hydroxyproline residues were radiolabeled after incorporation of ${ }^{14} \mathrm{C}$-proline. Analysis of the degradation of labeled extensin was by sizeexclusion chromatography on Sephacryl HR200. The ex-

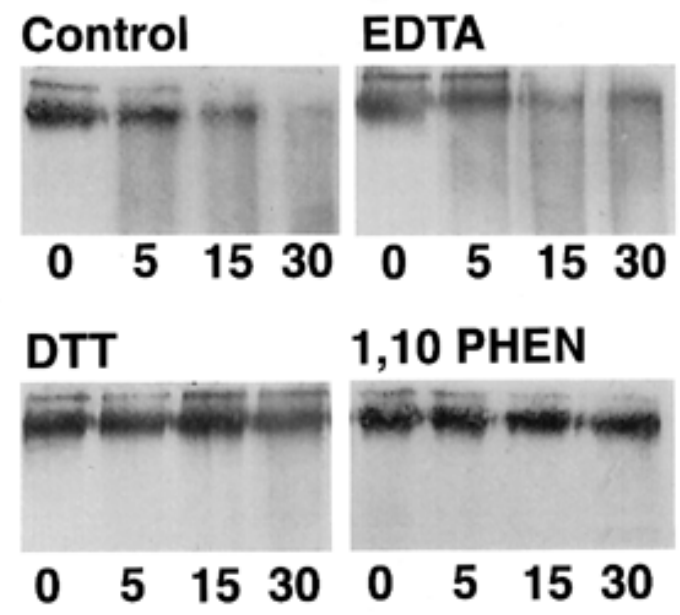

Fig. 4. Effects of various inhibitors on activity of the purified enzyme against the glycoprotein gp140. Degradation of gp140 was assayed by Western (immunoblot) analysis with the monoclonal antibody MAC204. Preparations of the enzyme were pretreated for $1 \mathrm{~h}$ at $25^{\circ} \mathrm{C}$ with buffer (control), $5 \mathrm{mM}$ EDTA, $5 \mathrm{mM}$ dithiothreitol (DTT), or $1 \mathrm{mM} \mathrm{1,10-}$ phenanthroline (1,10 phen) before assay for the time (in min) indicated beneath each lane. 
tensin preparation eluted in the blue dextran void volume of this column (Fig. 6A). Incubation with the $X$. campestris enzyme for $3 \mathrm{~h}$ caused a shift in the elution profile (Fig. $6 \mathrm{~A})$; although approximately $30 \%$ of the label remained in the blue dextran void volume, the larger proportion was included in the column, suggesting that at least partial degradation of the extensin had occurred. Extended incubations with the $X$. campestris enzyme did not alter this profile. Similar results were seen if labeled extensin was incubated overnight with trypsin (Fig. 6B). However, in this case a major degradation product, eluting with maximum concentration in fraction 29, was resolved. Boiled $X$. campestris enzyme preparations had no effect on the elution profile of the labeled substrate. These effects of the X. campestris enzyme on tomato extensin apparently occur without significant degradation of the carbohydrate part of the glycoprotein (see above), indicating that the enzyme is a protease cleaving the polypeptide backbone of the molecule.

\section{Inhibitor studies suggest that the enzyme is a metalloprotease.}

The optimum $\mathrm{pH}$ for enzyme activity was determined to be between 8 and 9 . As a consequence of these results, the sensitivity of the enzyme activity to inhibition by a range of protease inhibitors was tested with gp120, tomato extensin, and gp140 as substrates at $\mathrm{pH}$ 8.5. The activity against all three substrates was insensitive to inhibition by $1 \mathrm{mM}$ phenylmethylsulfonyl fluoride (PMSF), $14 \mu \mathrm{M}$ leupeptin, and $20 \mu \mathrm{M}$ pepstatin, was partially inhibited by $5 \mathrm{mM}$ EDTA, and completely inhibited by $5 \mathrm{mM}$ dithiothreitol (DTT) and $1 \mathrm{mM}$ 1,10-phenanthroline (Fig. 4). As 1,10-phenanthroline is a characteristic inhibitor of zinc metalloenzymes (Spungin and Blumberg 1989), these results suggest that the enzyme is a zinc-requiring metalloprotease. Inhibition by DTT suggests that the enzyme contains disulfide bonds that maintain its structure.

\section{DISCUSSION}

In this paper we describe the detection and characterization of a proteolytic enzyme from $X$. campestris that can degrade

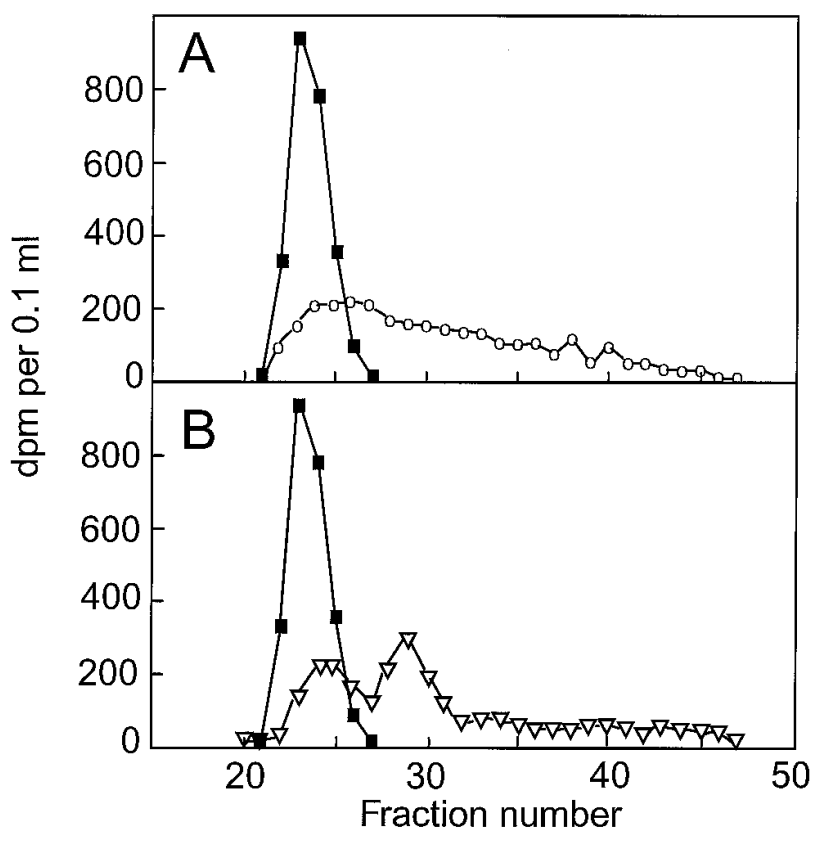

Fig. 6. Degradation of radiolabeled tomato extensin analyzed by sizeexclusion chromatography on Sephacryl HR200. Tomato extensin in which the proline and hydroxyproline residues were radiolabeled was obtained from suspension-cultured cells grown in the presence of U$\left[{ }^{14} \mathrm{C}\right]-\mathrm{L}-$ proline as described in Materials and Methods. A, Closed symbols: Labeled extensin incubated with the Xanthomonas campestris enzyme inactivated by boiling; Open symbols: Labeled extensin incubated with the $X$. campestris enzyme for $3 \mathrm{~h}$ at $37^{\circ} \mathrm{C}$. B, Closed symbols: As in A; Open symbols: Labeled extensin incubated with trypsin $(2 \mu \mathrm{g}, 24 \mathrm{~h}$ at $\left.37^{\circ} \mathrm{C}\right)$.
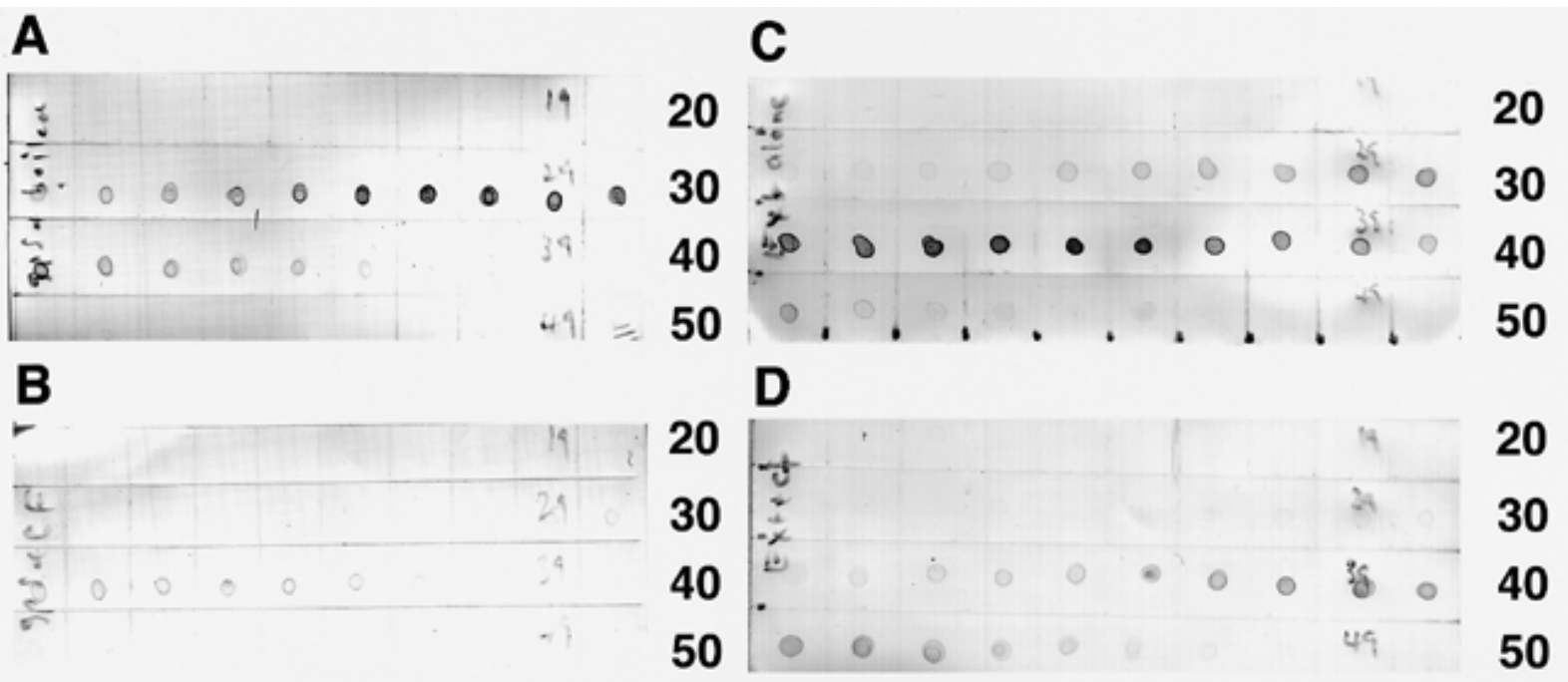

Fig. 5. Degradation of the Brassica campestris hydroxyproline-rich glycoprotein (HRGP) gpS-3 and potato extensin by the enzyme from Xanthomonas campestris pv. campestris. Degradation was analyzed by size-exclusion chromatography on Sephacryl HR400 followed by dot blot immunoanalysis of $1-\mu l$ aliquots of fractions. Fraction numbers are given on the right-hand side. A, gpS-3 incubated with enzyme inactivated by boiling. B, gpS-3 incubated with the active enzyme. C, Potato extensin incubated with enzyme inactivated by boiling. D, Potato extensin incubated with the active enzyme. A and $\mathbf{B}$, Probed with the monoclonal antibody JIM11. C and D, Probed with the monoclonal antibody MAC204. 
specific proline- or hydroxyproline-rich glycoproteins associated with the plant extracellular matrix. Accordingly, the enzyme can degrade gp120, a basic proline-rich glycoprotein associated with the vascular bundles of $B$. campestris petioles, but has no activity against gp45, an uncharacterized glycoprotein present in the extracellular matrix in leaves and petioles. In addition, the enzyme can partially degrade HRGPs such as the B. campestris glycoprotein gpS-3 and tomato and potato extensin, but has little or no activity against the solanaceous lectins that are chimeric proteins with an extensin-like HRGP domain fused to a lectin domain. The activity was distinct from that of the three previously characterized proteases of $X$. campestris pv. campestris that were identified by their action on skim milk and $\beta$-casein. This specificity demonstrates that the ability of $X$. campestris pv. campestris to degrade defense-related (glyco)proteins cannot be inferred from activity against these model substrates. Proteases specific for plant cell wall glycoproteins may have roles in disease development that are very different from those that can degrade $\beta$-casein.

The properties of the $X$. campestris enzyme are redolent of those of the gamete-lytic enzyme (GLE) described in Chlamydomonas reinhardtii (Jaenicke et al. 1987; Kinoshita et al. 1992). GLE is a zinc-requiring metalloprotease that selectively degrades HRGPs of the gamete wall during mating but has no activity on $\beta$-casein, hemoglobin, or other proteins. There are few reports of the ability of proteases from plant pathogens to degrade HRGPs. Willis et al. (1987) have described an extracellular protease from Erwinia carotovora subsp. carotovora that was active on gelatin and azocasein and could degrade HRGPs from potato and tomato. Heilbronn et al. (1995) purified an extracellular metalloprotease from another isolate of E. carotovora subsp. carotovora that was active against skim milk and azocasein and was able to (slowly) degrade the potato lectin. Although the doublet of bands seen in the final enzyme preparation may suggest that the enzyme has isoforms, we cannot rule out the possibility that the lower band was generated by the action of trace levels of other proteases (PRT2?) in the preparation or by gratuitous autodigestion, a problem commonly encountered during the purification of proteases.

The ability of the $X$. campestris enzyme to degrade some extracellular matrix glycoproteins but not others may depend on the presence or absence of appropriate (susceptible) peptide bonds and/or on the effects of different levels of glycosylation of each substrate on the accessibility of such bonds to the enzyme. For example, gp45, which is insensitive to the $X$. campestris enzyme, is degraded by the protease from the fungal pathogen Pyrenopeziza brassicae (A. Hunter and K. Johnstone, unpublished). In HRGPs such as extensin, the most characteristic amino acid sequence is the repeating pentasac-

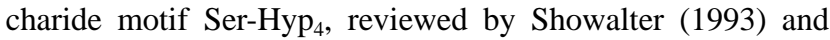
Kieliszewski and Lamport (1994). This sequence, which often occurs within larger repeating units, is thought to contribute to molecular inflexibility by stabilizing the polyproline-II conformation that gives extensin its extended rod structure. Blocks of hydroxyproline act as the major sites of glycosylation. Comparisons of extensin sequence data indicate that tetrahydroxyproline blocks are very highly arabinosylated, triand dihydroxyproline are less so, and single residues perhaps not at all (Kieliszewski et al. 1995). In tomato extensin, which

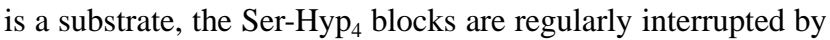
blocks of primary amino acids that may act as (nonglycosylated) flexible spacers (Smith et al. 1986). In contrast, the HRGP domain of potato lectin, which is not a substrate, contains long blocks of contiguous Hyp residues interrupted only by single Ser residues (Kieliszewski et al. 1994). It is possible that these differences in occurrence of different peptide bonds and/or in the degree of glycosylation between HRGPs determine substrate specificity. In this context it is interesting to note that trypsin can extensively degrade $\mathrm{P} 2$, one of the three soluble precursors of tomato extensin described by Smith et al. (1986), but has no apparent activity against precursor P1a. However, trypsin can extensively degrade deglycosylated P1a (Smith et al. 1986). It would be of interest to see if the protease from Erwinia carotovora subsp. carotovora described by Heilbronn et al. (1995) attacks the HRGP domain or the lectin domain of the potato lectin and whether this enzyme has greater activity against other HRGPs of the potato extracellular matrix such as extensin (Dey et al. 1997) and the bacterial agglutinin (Leach et al. 1982).

PRPs and HRGPs have been suggested to have two major roles in the defense of plants against microbes: agglutination and immobilization of bacteria through binding to cell surface glycoproteins; and alteration of cell wall properties either as a consequence of differentiation or in response to attempted infection leading to limitation or exclusion of pathogens. The ability of pathogens to degrade such glycoproteins may clearly compromise associated defense mechanisms. Demonstration of these activities in vitro is not, however, proof of their role in vivo. The purification of the enzyme described in this paper is a step toward cloning the cognate gene and the creation of specific mutants. These will allow a rigorous test of the role of the enzyme in the various phases of black rot pathogenesis.

\section{MATERIALS AND METHODS}

\section{Bacterial strains and growth conditions.}

The $X$. campestris pv. campestris strains used in this study were 8004, a rifampicin-resistant mutant of a wild-type isolate (Daniels et al. 1984) and 8524, a derivative of 8004 carrying a Tn5 insertion in prtA, the structural gene for the serine protease PRT1 (Liu et al. 1990). These strains were grown in peptone-yeast extract-glycerol medium (NYGB) (Daniels et al. $1984)$ at $28^{\circ} \mathrm{C}$. PRT1 free from other proteases was obtained from the agar medium of Escherichia coli JM107 carrying the recombinant plasmid pIJ3074 (which carries the prtA gene) as described by Tang et al. (1987). The metalloprotease PRT3 was obtained from culture supernatants of $X$. campestris pv. raphani strain 2345 as described by Dow et al. (1993).

\section{Monoclonal antibodies and immunological methods.}

The monoclonal antibodies used in this study were JIM11 and JIM20, originally described by Smallwood et al. (1994), and MAC204 and MAC236, originally described by VandenBosch et al. (1989). The immunological materials and methods used (Western [immunoblot] analysis, dot blotting, and secondary antibodies) and controls for the use of the antibodies are described by Davies et al. (1997a, 1997b). MAC204 recognizes a periodate-sensitive (carbohydrate) epitope present in a number of glycoproteins of the PRP and HRGP families. The nature of the epitope recognized by MAC236 is not 
known. JIM11 and JIM 20 recognize epitopes carried on, but not necessarily restricted to, HRGPs. It has been suggested that JIM11 and JIM20 recognize specific arabinosylation patterns of HRGPs (Smallwood et al. 1994).

\section{Protease and endoglucanase assays.}

Proteolytic activity against $\beta$-casein was measured by estimation of the degree and pattern of degradation of $\beta$-casein by SDS-PAGE as described previously (Dow et al. 1990, 1993). Assays were carried out in $50 \mathrm{mM}$ Tris- $\mathrm{HCl}$ buffer at $\mathrm{pH} 8$. The action of purified PRT1, PRT2, and PRT3 on $\beta$-casein produces characteristic patterns of peptides as revealed by SDS-PAGE on $14 \%$ gels and Coomassie blue staining. Endoglucanase activity was measured by a radial diffusion assay as described by Gough et al. (1988).

\section{Assay for degradation of the glycoprotein gp120.}

The ability of culture supernatants and fractions derived from them to degrade the proline-rich glycoprotein gp120 was routinely assessed by SDS-PAGE on $8 \%$ gels followed by immunoanalysis with MAC 204. The source of gp120 substrate for these routine assays was an extract from $B$. campestris petioles made with $100 \mathrm{mM}$ Tris- $\mathrm{HCl}$ buffer $\mathrm{pH} 8.5$ (Davies et al. 1997a). Two grams of petiole tissue was ground in a pestle and mortar with $2 \mathrm{ml}$ of buffer. The supernatant after centrifugation at $14,000 \times \mathrm{g}$ contains two glycoproteins (gp120 and gp45) that are immunoreactive with MAC204. One hundred microliters of this extract was mixed with $100 \mu \mathrm{l}$ of the fraction to be tested and was incubated at $37^{\circ} \mathrm{C}$. At different time points, samples were removed, mixed with an equal volume of SDS-PAGE loading buffer, and boiled. Samples were subjected to SDS-PAGE on $8 \%$ gels and transferred to nitrocellulose before immunoanalysis with MAC204.

\section{Other glycoprotein substrates.}

The solanaceous lectins used as substrates were obtained from Sigma (Poole, UK). The degradation of these glycoproteins, which are chimeric HRGPs, was assessed by SDSPAGE on $8 \%$ gels followed by immunoanalysis with JIM20. The concentration of lectin substrate in the assay was 25 $\mu \mathrm{g} / \mathrm{ml}$. The HRGP gpS-3 was purified from wounded $B$. campestris petioles as described by Davies et al. (1997b). Extensin isolated from tomato suspension cells by the method of Brownleader and Dey (1993) and from potato suspension cultures as described by Dey et al. (1997) was a gift from P. M. Dey (Royal Holloway and Bedford New College, University of London). The glycoprotein gp140 was isolated from wounded turnip tissue by essentially the same method used for extensin from carrot root tissue described by Stafstrom and Staehelin (1987). This involved extraction with $\mathrm{CaCl}_{2}$, precipitation with trichloroacetic acid, and successive cationexchange chromatography steps on Bio-Rex 70 and SP-5PW. The final step was fractionation with a Centricon-100 microconcentrator (Amicon, Beverley, MA) that separated gp140 from a retained glycoprotein. Analysis of the amino acid compositions of the gp140 fraction suggested that gp140 is related to gp120 and is a PRP (J. M. Dow, unpublished). gp140 was detected by monoclonal antibody MAC204 but not by JIM11.

Degradation of gp140 could be followed by Western analysis of reaction mixtures separated by SDS-PAGE with MAC204. Degradation of extensin and gpS-3, HRGPs that do not enter the resolving gel on $8 \%$ SDS-PAGE, was monitored by examining their behavior on size-exclusion gel chromatography on Sephacryl HR400 (Sigma, Poole, UK). The column $(1.5 \times 48 \mathrm{~cm})$ was equilibrated and eluted with $100 \mathrm{mM}$ Tris- $\mathrm{HCl} \mathrm{pH} 8.5$ containing $1 \mathrm{M} \mathrm{NaCl}$. Fractions $(1.2 \mathrm{ml})$ were collected at a flow rate of $12 \mathrm{ml}$ per h. The elution of the glycoproteins before and after enzyme treatment was monitored immunologically by dot blot analysis of the fractions with JIM11 or MAC204. Enzyme activity against different glycoproteins could also be detected by a progressive loss of immunoreactivity on dot blots of $1-\mu$ l aliquots of reaction mixtures.

\section{Radiolabeling of tomato extensin.}

Extensin radiolabeled in the protein moiety was obtained by addition of ${ }^{14} \mathrm{C}$-proline to tomato suspension cell cultures followed by isolation of extensin essentially as described by Brownleader and Dey (1993). Suspension cultures of tomato cells (hybrid of Lycopersicon esculentum and L. peruvianum) were grown in modified Murashige and Skoog tissue culture medium as described by Brownleader and Dey (1993). Conical flasks $(250 \mathrm{ml})$ containing $100 \mathrm{ml}$ of medium were subcultured with 7-day-old suspension cells and incubated at $19^{\circ} \mathrm{C}$ on a gyratory shaker. After 5 days growth, $370 \mathrm{KBq}(10$ $\mu \mathrm{Ci})$ of $\mathrm{U}-\left[{ }^{14} \mathrm{C}\right]$-L-proline $(9.18 \mathrm{GBq}$ per mmol; Amersham, Little Chalfont, UK) was added. The cells (approximately 20 $\mathrm{g}$ fresh wt) were harvested after a further 2 days by filtration on a Buchner funnel and were washed extensively with water. Extensin (along with other glycoproteins) was eluted from the intact cells with $50 \mathrm{mM} \mathrm{CaCl}$. Extensin was purified from this eluate by ion-exchange chromatography on CM-cellulose at $\mathrm{pH} 5.5$ followed by size-exclusion chromatography on a column of Sephacryl HR200 $(1.5 \times 48 \mathrm{~cm}$; Sigma, Poole, UK) equilibrated and eluted with $0.1 \mathrm{M}$ Tris- $\mathrm{HCl} \mathrm{pH} 8.5$ containing $1 \mathrm{M} \mathrm{NaCl}$. Samples were concentrated between chromatography steps with Centricon-30 microconcentrators (Amicon). Brownleader and Dey (1993) reported that extensin elutes in the high molecular weight void volume of the Sephacryl HR200 column. This was confirmed by immunoanalysis of the fractions from the Sephacryl HR200 column with the monoclonal antibody JIM11. Fractions containing extensin were pooled and concentrated to $1 \mathrm{ml}$ with Centricon-30 microconcentrators. No further fractionation was done. The preparation contained approximately $10 \mathrm{KBq}$ of radioactivity.

An aliquot of the extensin preparation was hydrolyzed with $6 \mathrm{~N} \mathrm{HCl}$ at $105^{\circ} \mathrm{C}$ for $24 \mathrm{~h}$ and the acid was removed by lyophilization. The sample was dissolved in distilled water and applied in a 3-cm-wide strip to a cellulose thin layer chromatography (TLC) plate (Eastman Kodak, Rochester, NY). The plate was developed in butanol-1-ol/acetic acid/water (12:3:5 by vol). After TLC, the plate was cut into strips $(3 \times 0.5 \mathrm{~cm})$ and the radioactivity in each was determined by scintillation counting in $3 \mathrm{ml}$ of Optiphase HiSafe 2 scintillation fluid (Wallac, Milton Keynes, UK) containing $0.2 \mathrm{ml}$ of water. The positions of authentic L-proline and 4-hydroxy-L-proline, which were run as standards, were detected by spraying with a $0.2 \%$ (wt/vol) solution of isatin (indole-2,3-dione) in butanol1-ol/acetic acid $(96: 4, \mathrm{vol} / \mathrm{vol})$ and heating at $105^{\circ} \mathrm{C}$ for 15 min. Two peaks of radioactivity with the mobilities of proline and hydroxyproline were detected; the ratio of labeled hydroxyproline to proline was approximately $4: 1$. 


\section{Analysis of the enzymatic degradation of radiolabeled extensin.}

The degradation of radiolabeled extensin was followed by size-exclusion chromatography on Sephacryl HR200. In a standard assay, radioactive extensin $(0.5 \mathrm{KBq}$ in $40 \mu \mathrm{l})$ was incubated with $40 \mu \mathrm{l}$ of an enzyme preparation at $\mathrm{pH} 8.5$ and $37^{\circ} \mathrm{C}$. At the end of the incubation the volume was made up to $1 \mathrm{ml}$ with $0.1 \mathrm{M}$ Tris- $\mathrm{HCl} \mathrm{pH} 8.5$ containing $1 \mathrm{M} \mathrm{NaCl}$. This sample was applied to a column of Sephacryl HR200 $(1.5 \times$ $48 \mathrm{~cm}$ ) that was equilibrated and eluted with $0.1 \mathrm{M}$ Tris- $\mathrm{HCl}$ $\mathrm{pH} 8.5$ containing $1 \mathrm{M} \mathrm{NaCl}$ at a flow rate of $12 \mathrm{ml}$ per $\mathrm{h}$. Fractions of $1.4 \mathrm{ml}$ were collected. For determination of radioactivity by scintillation counting, $0.1 \mathrm{ml}$ of each fraction was mixed with $0.1 \mathrm{ml}$ of water and $3 \mathrm{ml}$ of Optiphase HiSafe 2 scintillation fluid (Wallac, Milton Keynes, UK). For degradation by trypsin, $2 \mu \mathrm{g}$ of sequencing grade modified trypsin (Promega, Madison, WI) was used in $50 \mathrm{mM}$ Tris-HCl buffer $\mathrm{pH} 8.2$ at $37^{\circ} \mathrm{C}$ for $24 \mathrm{~h}$.

\section{Purification of an enzyme activity capable of degrading gp120.}

Cells of $X$. campestris pv. campestris strain 8524 were grown in 500-ml aliquots of NYGB medium at $28^{\circ} \mathrm{C}$ to an OD of 1.8. Cells were removed by centrifugation and the supernatants were concentrated by addition of ammonium sulfate to a final concentration of $600 \mathrm{~g} /$ liter. The precipitate that formed was harvested by centrifugation and was dialyzed overnight at $4^{\circ} \mathrm{C}$ against $10 \mathrm{mM}$ Tris- $\mathrm{HCl} \mathrm{pH}$ 8. The concentration factor was 40-fold. After dialysis, the buffer concentration was adjusted to $20 \mathrm{mM}$ by addition of $1 \mathrm{M}$ Tris- $\mathrm{HCl} \mathrm{pH}$. The sample was applied to a column $(2.5 \times 10 \mathrm{~cm})$ of DEAESephadex equilibrated with $20 \mathrm{mM}$ Tris- $\mathrm{HCl} \mathrm{pH} 8$ and eluted with the same buffer. The activity did not bind to the column under these conditions although a large proportion of the colored and viscous material in the sample did bind. The eluate was dialyzed overnight against distilled water, adjusted to $\mathrm{pH}$ 5 by the addition of $1 \mathrm{M}$ sodium acetate buffer $\mathrm{pH} 5$ to a final concentration of $20 \mathrm{mM}$. This sample was fractionated by ionexchange HPLC on a TSK SP-5PW column. The column was equilibrated with $20 \mathrm{mM}$ sodium acetate $\mathrm{pH} 5$ and all of the activity bound to the column at this $\mathrm{pH}$. The column was then eluted with a linear gradient of 0 to $0.4 \mathrm{M} \mathrm{NaCl}$ in $20 \mathrm{mM}$ sodium acetate buffer $\mathrm{pH} 5$ in a total volume of $40 \mathrm{ml}$. Fractions $(1 \mathrm{ml})$ were collected. Fractions that were active in the degradation of gp120 were pooled, concentrated with a Centricon30 microconcentrator, and resuspended in a final volume of $200 \mu \mathrm{l}$ of $20 \mathrm{mM}$ phosphate buffer $\mathrm{pH} 6.2$ containing $1 \mathrm{M}$ $\mathrm{NaCl}$. This sample was separated by size-exclusion HPLC on a column of $\mathrm{G} 3000 \mathrm{SW}_{\mathrm{XL}}$ equilibrated with the same buffer.

Proteins were electrophoretically transferred to ImmobilonP polyvinyl difluoride membranes (Millipore, Bedford, MA) for N-terminal amino acid sequencing as described by Southerton et al. (1993).

\section{HPAE chromatography of mono- and oligosaccharides.}

HPAE chromatography was carried out on a Carbo-Pac PA100 column (Dionex, Sunnyvale, CA) with pulsed amperometric detection of the eluate. The column was eluted with a linear gradient of sodium acetate in $150 \mathrm{mM} \mathrm{NaOH}$, conditions that resolve malto-oligosaccharides with degrees of polymerization from 2 to 7 .

\section{ACKNOWLEDGMENTS}

The Sainsbury Laboratory is supported by a grant from the Gatsby Charitable Foundation. This work was carried out according to the provisions of the Ministry of Agriculture, Fisheries and Food license PHF1185/8(48) issued under the Plant Health (Great Britain) Order 1987 (Statutory Instrument 1758). We thank Belinda Clarke for analysis of mono- and oligosaccharides by Dionex chromatography and Prakash Dey for gifts of tomato and potato extensins and tomato suspension cell cultures.

\section{LITERATURE CITED}

Ball, A. M., Ashby, A. M., Daniels, M. J., Ingram, D. S., and Johnstone, K. 1991. Evidence for the requirement of extracellular protease in the pathogenic interaction of Pyrenopeziza brassicae with oilseed rape. Physiol. Mol. Plant Pathol. 38:147-161.

Bowles, D. J. 1990. Defense-related proteins in higher plants. Annu. Rev. Biochem. 59:873-907

Bradley, D. J., Kjellbom, P., and Lamb, C. J. 1992. Elicitor- and woundinduced oxidative cross-linking of a proline-rich plant cell wall protein. Cell 70:21-30.

Brisson, L. F., Tenhaken, R., and Lamb, C. J. 1994. Functions of oxidative cross-linking of cell wall structural proteins in plant disease resistance. Plant Cell 6:1703-1712.

Brownleader, M. D., and Dey, P. M. 1993. Purification of extensin from cell walls of tomato (hybrid of Lycopersicon esculentum and L. peruvianum) cells in suspension culture. Planta 191:457-469.

Daniels, M. J., Barber, C. E., Turner, P. C., Sawczyc, M. K., Byrde, R. J. W., and Fielding, A. H. 1984. Cloning of genes involved in pathogenicity of Xanthomonas campestris pv. campestris using the broad host range cosmid pLAFR1. EMBO J. 3:3323-3328.

Davies, H. A., Daniels, M. J., and Dow, J. M. 1997a. A novel prolinerich glycoprotein associated with the extracellular matrix of vascular bundles of Brassica petioles. Planta 202:28-35.

Davies, H. A., Daniels, M. J., and Dow, J. M. 1997b. Induction of extracellular matrix glycoproteins in Brassica petioles by wounding and in response to Xanthomonas campestris. Mol. Plant-Microbe Interact. 7: $812-820$.

Dey, P. M., Brownleader, M. D., Pantelides, A. T., Trevan, M., Smith, J. J., and Saddler, G. 1997. Extensin from suspension-cultured potato cells: A hydroxyproline-rich glycoprotein, devoid of agglutinin activity. Planta 202:179-187.

Dow, J. M., Clarke, B. R., Milligan, D. E., Tang, J.-L., and Daniels, M. J. 1990. Extracellular proteases from Xanthomonas campestris pv. campestris, the black rot pathogen. Appl. Environ. Microbiol. 56: 2994-2998.

Dow, J. M., Fan, M.-J., Newman, M.-A., and Daniels, M. J. 1993. Differential expression of conserved protease genes in crucifer-attacking pathovars of Xanthomonas campestris. Appl. Environ. Microbiol. 59: 3996-4003.

Esquerré-Tugayé, M. T., Lafitte, C., Mazau, D., Toppan, A., and Touzé, A. 1979. Cell surfaces in plant-microorganism interactions. II. Evidence for the accumulation of hydroxyproline-rich glycoproteins in the cell wall of diseased plants as a defense mechanism. Plant Physiol. 64:320-326.

Gough, C. L., Dow, J. M., Barber, C. E., and Daniels, M. J. 1988. Cloning of two endoglucanase genes of Xanthomonas campestris pv. campestris: Analysis of the role of the major endoglucanase in pathogenesis. Mol. Plant-Microbe Interact. 1:275-281.

Heilbronn, J., Johnstone, D. J., Dunbar, B., and Lyon, G. D. 1995. Purification of a metalloprotease produced by Erwinia carotovora spp. carotovora and the degradation of the potato lectin in vitro. Physiol. Mol. Plant Pathol. 47:285-292.

Jaenicke, L., Kuhne, W., Spessert, R., Wahle, U., and Waffenschmidt, S. 1987. Cell-wall specific enzymes (autolysins) of Chlamydomonas reinhardtii are (hydroxy)proline-specific proteases. Eur. J. Biochem. 170:485-491.

Kieliszewski, M. J., and Lamport, D. T. A. 1994. Extensin: Repetitive motifs, functional sites, post-translational codes, and phylogeny. Plant J. 5:157-172.

Kieliszewski, M. J., O’Neill, M., Leykam, J., and Orlando, R. 1994. Potato lectin: A modular protein sharing sequence similarities with the 
extensin family, the hevein lectin family, and snake venom disintegrases (platelet agglutinating factor). Plant J. 5:849-861.

Kieliszewski, M. J., O’Neill, M., Leykam, J., and Orlando, R. 1995. Tandem mass spectrometry and structural elucidation of glycopeptides from a hydroxyproline-rich plant cell wall glycoprotein indicate that contiguous hydroxyproline residues are the major sites of hydroxyproline O-arabinosylation. J. Biol. Chem. 270:2541-2549.

Kinoshita, T., Fukuzawa, H., Shimada, T., Saito, T., and Matsuda, Y. 1992. Primary structure and expression of a gamete lytic enzyme in Chlamydomonas reinhardtii: Similarity of functional domains to matrix metalloproteases. Proc. Natl. Acad. Sci. USA 89:4693-4697.

Leach, J. E., Cantrell, M. A., and Sequeira, L. 1982. Hydroxyprolinerich bacterial agglutinin from potato. Plant Physiol. 70:1353-1358.

Liu, Y.-N., Tang, J.-L., Clarke, B. R., Dow, J. M., and Daniels, M. J. 1990. A multipurpose broad host range cloning vector and its use to characterise an extracellular protease gene of Xanthomonas campestris pathovar campestris. Mol. Gen. Genet. 220:433-440.

Mellon, J. E., and Helgeson, J. P. 1982. Interaction of a hydroxyprolinerich glycoprotein from tobacco callus with potential pathogens. Plant Physiol. 70:401-405.

Millar, D. J., Slabas, A. R., Sidebottom, C., Smith, C. G., Allen, A. K., and Bolwell, G. P. 1992. A major stress-inducible $\mathrm{M}_{\mathrm{R}}-42000$ wall glycoprotein of French bean (Phaseolus vulgaris L.). Planta 187:176-184.

Showalter, A. M. 1993. Structure and function of plant cell wall proteins. Plant Cell 5:9-23

Showalter, A. M., Bell, J. N., Cramer, C. L., Bailey, J. A., Varner, J. E., and Lamb, C. J. 1985. Accumulation of hydroxyproline-rich glycoprotein mRNAs in response to fungal elicitor and infection. Proc. Natl. Acad. Sci. USA 82:6551-6555.

Smallwood, M., Beven, A., Donovan, N., Neill, S. J., Peart, J., Roberts, K., and Knox, J. P. 1994. Localization of cell wall proteins in relation to the developmental anatomy of the carrot root apex. Plant J. 5:237-246.
Smith, J. J., Muldoon, E. P., Willard, J. J., and Lamport, D. T. A. 1986. Tomato extensin precursors $\mathrm{P} 1$ and $\mathrm{P} 2$ are highly periodic structures. Phytochemistry 25:1021-1030.

Southerton, S., Osbourn, A. E., Dow, J. M., and Daniels, M. J. 1993. Two xylanases from Gaeumannomyces graminis with identical Nterminal amino acid sequence. Physiol. Mol. Plant Pathol. 42:97-107.

Spungin, A., and Blumberg, B. 1989. Streptomyces griseus aminopeptidase is a calcium-activated zinc metalloprotein: Purification and properties of the enzyme. Eur. J. Biochem. 183:471-477.

Stafstrom, J. P., and Staehelin, L. A. 1987. A second extensin-like hydroxyproline-rich glycoprotein from carrot cell walls. Plant Physiol. 84:820-825.

Swords, K. M. M., and Staehelin, L. A. 1993. Complementary immunolocalization patterns of cell wall hydroxyproline-rich glycoproteins studied with the use of antibodies directed against different carbohydrate epitopes. Plant Physiol. 102:891-901.

Tang, J.-L., Gough, C. L., Barber, C. E., Dow, J. M., and Daniels, M. J. 1987. Molecular cloning of protease genes from Xanthomonas campestris pv. campestris: Expression in Escherichia coli and role in pathogenesis. Mol. Gen. Genet. 210:443-448.

VandenBosch, K. A., Bradley, D. J., Perotto, S., Butcher, G. W., and Brewin, N. J. 1989. Common components of the infection thread matrix and the intercellular space identified by immunochemical analysis of pea nodules and uninfected roots. EMBO J. 8:335-342.

Walton, J. D. 1994. Deconstructing the cell wall. Plant Physiol. 104: 1113-1118.

Williams, P. H. 1980. Black rot: A continuing threat to world crucifers. Plant Dis. 64:736-742.

Willis, J. W., Engwall, J. K., Leach, J. E., and Chatterjee, A. K. 1987. Extracellular protease of Erwinia carotovora subsp. carotovora: Characterization and involvement in soft-rot pathogenesis. (Abstr.) Phytopathology 77:1736. 